\title{
La fiscalidad como fuente de información del comercio y el tráfico colonial (1573-1650): el almojarifazgo de la Caja Real de Veracruz
}

\author{
Taxation as a Source of Information on Trade \\ and Colonial Traffic (1573-1650): \\ The Almojarifazgo of the Real Caja de Veracruz
}

\author{
Emiliano Gil \\ Universidad San Francisco de Quito, Quito, Ecuador, \\ email: emigilblanco@gmail.com
}

Resumen. El estudio se centra en el puerto novohispano de Veracruz, que fungió como reexpedidor de las mercancías negociadas en México, y estudia la documentación del impuesto de la Caja Real de Veracruz. Esta nos da información de las embarcaciones que entraban y salían, sus destinos u orígenes y la cantidad pagada de almojarifazgo, sin hacer distinciones. Al ser un porcentaje cobrado sobre el valor de las mercancías, se ha calculado el valor total negociado en el puerto entre 1573 y 1650 . A pesar del fraude y del contrabando que hubo durante todo el periodo, puede considerarse una fuente de información fiable y aproximada del comercio novohispano. El objetivo de la investigación, utilizando los datos que aporta el almojarifazgo, es cuantificar la cantidad recaudada, establecer los diferentes periodos de auge y crisis en la recaudación, discriminando importaciones y exportaciones del comercio intercontinental y colonial.

Palabras clave: almojarifazgo; fiscalidad; comercio colonial.

Abstract. The study focuses on the new-Hispanic port of Veracruz, which served as the re-shipper of the goods negotiated in Mexico, studying the documentation of the tax of the Real Caja de Veracruz. It gives us information about incoming and outgoing ships, their destinations or origins, and the amount paid for almojarifazgo, without distinctions. As a percentage charged on the value of the merchandises, the total value negotiated in the port between 1573 and 1650 has been calculated. In spite of the fraud and the contraband that was during all the period, it can be considered a source of reliable and approximate information of the new Spanish trade. The objective of the research, using the data provided by the almojarifazgo is to quantify the amount collected, establish the different periods of boom and crisis in the collection, discriminating imports and exports of intercontinental and colonial trade.

Keywords: almojarifazgo; tax law; trade commerce.

JEL: N46; N76.

Am. Lat. Hist. Econ., sept.-dic., 2018, pp. 133-159 | DOI: 10.18232/alhe.919 
Fecha de recepción: 29 de agosto de 2017. Fecha de aceptación: 1 de noviembre de 2017.

Organismos colaboradores: Universidad de Alcalá, Banco de España, Agencia Española de Cooperación Internacional para el Desarrollo, Universidad San Francisco de Quito.

La serie de almojarifazgo percibido en Veracruz sobre los movimientos de los navíos con España y América permanece casi constante. Nada hace pensar en una modificación radical de la eficacia de las obligaciones fiscales.

(Chaunu, p. 542).

\section{INTRODUCCIÓN}

$\tau$ a Hacienda Real durante la colonia gravaba el comercio marítimo con varios impuestos, los más importantes fueron la avería y el almojarifazgo. Este último lo hizo directamente sobre las mercancías negociadas. La información que da el impuesto es una rica fuente para interpretar tanto el comercio colonial como el intercontinental. Buscamos establecer con este estudio una cuantificación y periodificación del impuesto de almojarifazgo recaudado para, en una posterior publicación, poder calcular el valor global de las mercancías negociadas en el puerto de Veracruz entre 1573 y 1650 y su distribución por terminales portuarias. Pretendemos profundizar en el comercio de Veracruz y su área de influencia para poder ver el impacto que tuvo la crisis de 1621 en el puerto. Para ello hemos utilizado como fuente las cartas-cuenta de la Caja Real de Veracruz existentes en la sección de Contaduría del Archivo General de Indias de Sevilla. Si bien es verdad que esta fuente es limitada al no tener en cuenta el fraude y contrabando producido en el circuito, en verdad puede suponer una aproximación a las cifras que se negociaron.

El mantenimiento del sistema comercial español con América en buena parte estuvo basado en la recaudación de una serie de impuestos cobrados sobre el valor de las mercancías en él negociadas, como la avería, el derecho de toneladas, el almirantazgo, la lonja o el almojarifazgo. Todos ellos cubrieron una función específica dentro del sistema. La avería tuvo como origen la financiación de las armadas que protegían los convoyes de la Carrera de Indias. El derecho de toneladas financió los gastos de la Universidad de Mareantes de Sevilla, mientras que el almirantazgo hizo lo propio con el salario de los almirantes de Castilla y la lonja con el consulado.

De todos estos impuestos, el almojarifazgo o renta del mar fue el único que no se cobró con un fin específico, sino que financió la burocracia y 
los gastos de la corona castellana en general, tanto en América como en la metrópoli. Su origen se remonta a los tiempos de la dominación árabe de la península. Con la conquista de la ciudad de Sevilla en 1248 por Fernando III el Santo, este impuesto pasó a engrosar la Hacienda Real y, más tarde, fue regulado por Alfonso X. Desde un principio el sistema de cobro de este impuesto variaba de un puerto a otro y se realizaba a través del arrendamiento del mismo por terceras personas.

Para comprender mejor lo que fue el almojarifazgo en general para el periodo estudiado debemos destacar los estudios de Emiliano Gil (1986, 1990, 1993, 1997), quien además ha trabajado sobre la historia del puerto de Veracruz y su comercio, Manuel Moreyra (1944), Manuel J. Ayala (1988) o Luis Salas (2007, 2012), sobre el almojarifazgo en Sevilla y Sanlúcar de Barrameda. Existe, como puede apreciarse, una escasa historiografía sobre el almojarifazgo para los siglos XVI y XVII en México. No pasa lo mismo con otros impuestos, como la alcabala (Celaya, 2010; Valle, 2003) o la avería (Céspedes, 1945). Por el contrario, el siglo XVIII se ha estudiado más profundamente, no sólo Nueva España, sino otras zonas americanas que comenzaron su expansión en ese siglo, como es el caso del Río de la Plata. La mayor parte utiliza otras fuentes fiscales o los registros de embarcaciones (Jumar, 2004).

Tras el descubrimiento de América, los reyes católicos extendieron en 1497 el cobro del almojarifazgo al comercio de las mercancías enviadas a ese continente, eximiendo del pago de este y de cualquier otro derecho al comercio intercolonial y a todos los productos americanos exportados desde los nuevos territorios anexionados hacia la metrópoli sin excepción (Antúnez, 1797, pp. 209-210; Fuentes, 1991, p. 39; Haring, 1979, p. 105). En un principio, la recaudación de este impuesto estuvo destinada a la financiación de la administración colonial, aunque en un principio la corona lo impuso para justificar los elevados gastos de su política. ${ }^{1}$

La fecha exacta de su implantación en América nos es desconocida, pero el avance de la conquista y colonización de los nuevos territorios fueron parejos con la constitución de la Real Hacienda. De esta manera, las islas del Caribe presenciaron de primera mano el poder fiscal castellano, al haber sido los primeros territorios descubiertos y conquistados, para pasar después

\footnotetext{
1 "ya saveis y teneis bien entendido el estado y termino en que las nuestras rrentas rreales y nuestro patrimonio y hazienda se halla y quanto esta todo consumido y acabado y enbarcado y la poca hazienda y facultad que tenemos ni nos queda para el sostenimiento de las cosas hordinarias y forçosas y para la promision de las muchas y muy grandes estraordinarias que nos ocurren continuamente y que ansi para la defensa de la causa publica de la cristiandad y rreligion y para la conserbacion y sostenimiento de nuestros estados y señorios a sido y es necesario y crecer y acreçentar las nuestras rrentas y derechos rreales aquellos que mas justamente y con menos dano y perjuizio se pueda hacer..." Contaduría, leg. 878. Carta enviada por los contadores de la Real Caja al Consejo. Archivo General de Indias (en adelante AGI).
} 
a Nueva España y, más tarde, a América Central y del Sur. Tenemos noticias de que en 1528 ya se cobraba el almojarifazgo en el virreinato novohispano y en 1543 en el peruano (Lorenzo, 1980, p. 364).

A partir de la real cédula del 28 de febrero de 1543 (Antúnez, 1797, pp. 210-211), el cobro de este derecho fue extendido a todos los productos importados de Europa, permaneciendo libre de cargas el comercio de exportación y el intercolonial. Al mismo tiempo, esta real cédula introdujo en América otro impuesto sobre el valor de las mercancías, la alcabala, que gravaba la primera venta de los artículos en los mercados americanos. Los porcentajes de cobro del almojarifazgo quedaron establecidos en $2.5 \%$ de las mercancías declaradas de salida de Sevilla y en 5\% de entrada en América (Antúnez, 1797, p. 21; Haring, 1979, pp. 105-106).

Como puede apreciarse, la real cédula de 1543 no modificó el sistema establecido en 1497. La novedad radicó en la forma de recaudar el almojarifazgo, parte en el puerto de salida y el resto en el de llegada, cuando con anterioridad era recaudado en su totalidad en el puerto sevillano. A este 7.5\% de almojarifazgo hay que añadir $10 \%$ de alcabala de la primera venta, con lo que en realidad quedaban gravadas las mercancías en $17.5 \%$ de su valor en destino. En los casos que los productos importados de la metrópoli fueran reexportados hacia otros puertos americanos, la Real Hacienda los volvía a gravar con 5\% más.

Una vez que empezaron a exportarse determinados productos agrícolas americanos, inicio de un comercio de tornaviaje hacia Europa, mucho más voluminoso, es cuando se aplicó el impuesto. Tras una serie de consultas del rey, realizadas entre 1559 y 1566 (Borah, 1975, p. 218), y previa consulta al Consejo de Indias, decidió reorganizar la recaudación del almojarifazgo. Se expidieron la real cédula del 29 de mayo de $1566^{2}$ y la real provisión de 28 de diciembre de $1568 .{ }^{3}$ La corona buscó en el comercio americano una ampliación de sus ingresos, ya que este apenas se encontraba expuesto a la presión fiscal del momento, y también porque en él se obtenían grandes beneficios y privilegios.

La real cédula de 1566 duplicó los porcentajes que debían cobrarse de almojarifazgo para el comercio intercontinental, fijándolos en 5\% de salida de Sevilla, antes $2.5 \%$, y de $10 \%$ de entrada en los puertos habilitados para el

${ }^{2}$ Esta real cédula se refiere al cobro del almojarifazgo del comercio intercontinental y fue expedida el 24 de junio de 1566, recibida por la Real Audiencia de México el 21 de septiembre del mismo año, enviada a Veracruz el día siguiente y asentada en los libros de la Real Caja del puerto por el tesorero Rodrigo Fránquez el 27 de agosto de 1573. Contaduría, Real Caja de Veracruz, leg. 878. Recopilación de Leyes de los reynos de Las Indias, libro VIII, tít. XV, Ley I. AGI.

${ }^{3}$ Esta real provisión establece el almojarifazgo para el comercio intercolonial. Su desarrollo se produce por la cédula del 11 de octubre de 1570. En Nueva España el virrey Enríquez la impone por provisión de 6 de abril de 1571 dada en la ciudad de México el día 30 de septiembre de 1571. Contaduría, Caja Real de Veracruz, leg. 878. Recopilación, libro VIII, tít. XV, Ley I. AGI. 
comercio con América, antes 5\%. Asimismo, los vinos andaluces, que constituyeron uno de los productos más exportados a las colonias americanas, vieron también gravado su comercio con $10 \%$ adicional tanto en Sevilla como en América. ${ }^{4}$

La real provisión de 1568 impuso por primera vez el almojarifazgo al comercio intercolonial, que en Nueva España comenzó a aplicarse dentro de la reforma general del virrey Martín Enríquez (García-Abasolo, 1983, pp. 217228) y en Perú por el licenciado Lope García de Castro (1564-1569) bajo el mandato del virrey Francisco de Toledo. Las instrucciones que desarrollaron el nuevo sistema contributivo, según Moreyra (1944, p. 17) y Borah (1975, p. 218), no llegaron a los alcaldes mayores de los puertos hasta 1571.

Según esta provisión las mercancías exportadas hacia otros puertos coloniales debían pagar a la Real Hacienda 2.5\% de su valor declarado en el puerto de salida, tal y como estaba estipulado para el comercio de exportación hacia Europa. Las mercancías introducidas o importadas de procedencia colonial pagaron desde entonces $5 \%$ de su valor en el puerto de destino. Mientras que, por otro lado, los productos europeos reexportados entre las mismas colonias americanas pagaron a la Real Hacienda 5\%, no sobre su valor declarado en el puerto de destino, sino sobre la diferencia de precios existente entre este último y el puerto de origen manifestado en los registros de las embarcaciones. A la par, y para que se llevase a cabo con fidelidad la recaudación del almojarifazgo, la corona extendió obligatoriamente la elaboración de los registros para el tráfico intercolonial. ${ }^{5}$ Con esta real provisión quedó cerrado el circuito de recaudación de los derechos de almojarifazgo del comercio indiano hasta el final del siglo XVIII. ${ }^{6}$

4 “....abemos acordado de crecer y acrezentar los derechos del nuestro almojarifazgo de yndias sobre las mercançias y en la forma y manera que en esta nuestra çedula se contiene conbiene a saver que todas las mercancias que se cargaren y llebaren a las nuestras yndias por los puertos y lugares donde conforme a lo que por nos esta probeido hordenado y se pueden y deben cargar de mas de los dos y medio por çiento que hasta aqui conforme a los arançeles se an pagado y paguen de aqui adelante por el tiempo que fuere nuestra boluntad otros dos y medio que sean por todos çinco y que los puertos y lugares de las yndias donde conforme a lo que por nos esta hordenado e se descarguen las dichas mercancias y se cobre de almoxarifazgo cinco por ciento demas y allende de los dichos cinco se cobren otros cinco que son por todos diez y juntos con lo que aca conviene a lo que dicho es sea de llevar son quinze por ciento y que otrosi de los binos que se cargan para las yndias de mas de los dos y medio que se paguen por ciento aca se paguen otros siete y medio que por todos son diez y alla en los dichos puertos de las yndias se paguen otros diez que seran en los dichos vinos veinte". Contaduría, leg. 878. Los recaudos de los nuevos derechos de almoxarifazgo a dos y medio por çiento. AGI.

${ }^{5}$ Los recaudos de los nuevos derechos de almojarifazgo a dos y medio por ciento. Contaduría, Caja Real de Veracruz, leg. 878. AGI.

6 "que las mercancias y cosas que se nabegan y nabegaren de aqui adelante destas partes para los rreinos despaña de que su magestad entiende que hasta agora no se le a pasado aca ningun derecho de almoxarifasgo de la salida dellas / manda que de aqui adelante se les paguen derechos de almoxarifasgo dos y medio por çiento de las tales mercaderias al tiempo de sacarlas y cargarlas para aquellos rreinos y del verdadero valor quaca tubieren lo cual por agora no se 
La imposición de estos nuevos aranceles no fue, ni mucho menos, aceptada por quienes más directamente se encontraban afectados, los mercaderes. En Nueva España los comerciantes dirigieron una relación al virrey Enríquez, que a su vez envió a Castilla, en la que exponían las posibles consecuencias de la nueva recaudación sobre el comercio por tan sustancial aumento de las imposiciones (García-Abasolo, 1983, pp. 221-222). En el virreinato peruano la oposición de los comerciantes y de la Real Audiencia al nuevo almojarifazgo fue tal que hubo de retrasarse su aplicación hasta 1566 rebajado a 1\% en vez de el 5\% estipulado (Moreyra, 1944, p. 17). También, como consecuencia de estas protestas, se redujo 7.5\% el arancel a los vinos sevillanos (Antúnez, 1797, p. 212). ${ }^{7}$

En realidad, las repercusiones económicas del incremento del almojarifazgo en el comercio americano fueron bien diferentes de las alarmistas relaciones de los comerciantes de ambos continentes.

\section{EXENCIONES Y REDUCCIONES EN EL COBRO DEL ALMOJARIFAZGO}

A pesar de la obligatoriedad del cobro del impuesto a todos los productos, siempre hubo exenciones e, incluso, se concretó a determinados puertos por causas políticas o económicas. Por supuesto que no pagaron almojarifazgo ninguno de aquellos productos con destino al servicio de la corona, tanto en América como en la península ibérica, así como las municiones, bastimentos y pertrechos para las embarcaciones de la Carrera de Indias (Antúnez, 1797, pp. 215, 218). ${ }^{8} \mathrm{Su}$ aplicación en un principio se realizó sobre los navíos que iban de escolta de los convoyes para luego extenderse a todos los que participaron en el tráfico indiano.

entienda con las yslas que tienen pribilegios y çedulas particulares de su magestad de çiertas franquezas para lo que toca a los frutos de sus labranças y crianças que esto se les a de guardar por el tiempo y de la manera que en ellos se contiene yten que de todas las mercaderias y cosas que se nabegaren de aqui adelante por mar desta nueva españa de piru y panama y nombre de dios y del peru panama y nombre de dios desta nueva españa y otras probinçias yslas e partes por los mares del sur y norte de que hasta aqui no se aya pagado derechos de almoxarifazgo a las entradas ni salidas manda que de aqui adelante se le paguen de derechos de almoxarifasgo dos y medio por çiento de salida en donde se sacaren u cargaren y çinco por çiento de entrada en las partes donde se llevaren y descargaren que son los derechos antiguos de su almoxarifasgo y que los dichos derechos se paguen del verdadero balor que tubieren las dichas mercaderias donde se cargaren y descargaren al tiempo la salida y entrada dellas" Contaduría, leg. 878. Los recaudos de los nuevos derechos de almoxarifazgo a dos y medio por çiento. AGI.

${ }^{7}$ Cédula del 25 de enero de 1567. Antúnez, 1797, p. 212.

${ }^{8}$ Las mercancías enviadas por la corona estaban exentas desde 1507. Cédula del 27 de abril de 1574, ratificada por las cédulas del 14 de septiembre de 1613 y 12 de diciembre de 1619. Recopilación, libro VIII, tít. XV, Ley XXVI. 
Desde muy temprano las pertenencias personales de los viajeros estuvieron exentas del impuesto, siempre y cuando no fueran vendidos en destino. Los oficiales reales se encargaron de vigilar que no se contravinieren estas normas. En caso de realizar la venta de alguna pertenencia, esta se penalizó con el cobro del duplo del porcentaje del almojarifazgo respectivo. Cuando hicieran de intermediarios de terceras personas, las mercancías eran incautadas junto con la mitad de los bienes del denunciado, que se repartían a terceras partes entre la corona, el juez y el denunciante. ${ }^{9}$

Otro artículo parcialmente exento del pago del almojarifazgo fue el libro, continuando un antiguo privilegio establecido por los reyes católicos (1480) que eximía de todos los impuestos a los libros introducidos en Castilla por mar y por tierra (Antúnez, 1797, p. 218; Haring, 1979, p. 106). ${ }^{10}$ En América estuvieron gravados por la avería, como se hacía con la importación de azogues. Para los primeros existió en Veracruz una segunda aduana, la de la Inquisición, con el fin de filtrar aquellos no acordes con las doctrinas rectoras de la Iglesia católica del momento (Miranda, 1962, p. 75).

También determinados puertos vieron reducidos los almojarifazgos con el fin de potenciar su comercio. La política de la corona de crear un comercio monopolista capitalizado por un único puerto de salida y otro de entrada hizo que el resto de las colonias, salvo excepciones, quedaran alejadas de las rutas mercantiles hasta el Decreto de Libre Comercio de 1778. Esta carencia se suplió con el contrabando con comerciantes extranjeros y por contados contactos comerciales que mantuvieron las colonias entre sí. Con este fin, la corona concedió reducciones en el impuesto, sobre todo de salida, durante determinados periodos para potenciar el comercio legal. Este privilegio sólo estuvo dirigido a los productos exportados con destino a la metrópoli según evidencian Antúnez (1797, pp. 213-214), Lorenzo (1980, pp. 371-372) y Haring (1979, p. 107), en referencia a las cédulas del 2 de febrero de 1561 y 8 de mayo de 1577.

Estas reducciones también las encontramos en varios puertos venezolanos a finales del siglo XVI. Concretamente, se redujeron a la mitad las tasas del impuesto para el comercio intercolonial. Cumaná obtuvo este privilegio en 1589, Margarita en 1592, Caracas en 1592 y 1597, Río Hacha (Nuevo Reino de Granada) en 1596 y Nueva Andalucía en 1597 (Arcila, 1993, p. 39; Haring, 1979, p. 107; Lorenzo, 1980, pp. 371-372). Cartagena recibió permisos para reducir el cobro del impuesto en 1535,1539 y 1540 , en este

${ }^{9}$ Cédulas del 15 de diciembre de 1531 para los clérigos y del 28 de febrero de 1543 para el resto de los pasajeros. Recopilación, libro VIII, tít. XV, Leyes XXVIII y XXIX.

${ }^{10}$ Cédula del 4 de noviembre de 1548. Recopilación, libro VIII, tít. XV, Ley XXVII. 
caso para mercancías que fomentasen la agricultura y la ganadería locales (Borrego, 1983, p. 62). ${ }^{11}$

Puerto Rico recibió esta merced en 1567, 1606, 1611, 1625, 1632 y 1636 (Lorenzo, 1980 pp. 371-372; Vila, 1974, pp. 224-225), concretamente se redujo el almojarifazgo a la mitad para incentivar el comercio de cueros y azúcar de la isla. El puerto cubano de La Habana también vio concedido este derecho para los años 1569, 1577, 1589 y 1595 (Lorenzo, 1980, pp. 371-372).

\section{EVALUACIÓN DEL VALOR DE LAS MERCANCÍAS Y COBRO DEL IMPUESTO}

Al ser un impuesto sobre el valor de las mercancías, los oficiales reales calcularon el mismo a partir de los precios en el puerto de origen o de destino a los 30 días de ser embarcadas o desembarcadas (Antúnez, 1797, pp. 235-236; García, 2014, pp. 479-481). ${ }^{12}$ La fuente para su cálculo fueron los registros de las embarcaciones o una declaración jurada del comerciante; según Antúnez (1979, p. 233) y Lorenzo (1980, pp. 378 y 379) en referencia a la contaduría de la Caja Real de Veracruz. ${ }^{13}$ En ellos se incluían, con día, mes y año, las mercancías que transportaban y su valor, declarando fardo a fardo y caja a caja. Esta declaración no se comprobaba de forma sistemática, ni se exigían las facturas de compra y venta, a no ser que hubiera pruebas de fraude o denuncia.

Esta no comprobación de lo declarado constituyó un privilegio de los comerciantes y cargadores del comercio de Indias. Muy pocas veces fueron revisadas por los oficiales reales. Para evitarlo, estaban los respectivos consulados que con sus donativos y peticiones a la corona conseguían acabar con el funcionario más celoso y obtener mayores privilegios para su comercio. Se alegaba en su favor los retrasos que originarían tales averiguaciones en la carga y descarga de las flotas y embarcaciones, con el perjuicio que esta demora causaría en sus beneficios y en la recaudación de los impuestos. Para conceder estos privilegios, la corona emitió en 1586 una cédula por la que instó a sus funcionarios a no abrir los fardos cargados y a acelerar el despacho de flotas y embarcaciones (Antúnez, 1797, pp. 237-238).

Este privilegio encontró la oposición de algunos funcionarios reales. Así, en 1596 la Casa de la Contratación se opuso a que oficiales reales investigaran el contenido de fardos y cajas cargados en las embarcaciones. Misma situación se repitió en 1604, terminando esta polémica en 1609 con una

\footnotetext{
${ }^{11}$ Reales cédulas del 8 de diciembre de 1533,8 de noviembre de 1539 y 11 de febrero de 1540 (Borrego, 1983, p. 62).

${ }^{12}$ Ordenanzas de 1554 y cédula del 22 de diciembre de 1579. Antúnez, 1797, pp. 235 y 236.

${ }^{13}$ Contaduría, Caja Real de Veracruz, Leg. 878. AGI.
} 
cédula prohibiendo la inspección de lo declarado en los registros (Antúnez, 1797, p. 241). Como ejemplo, una relación de dos oficiales de la Real Caja de México de esta época nos muestra muy acertadamente esta situación. ${ }^{14}$

Tal privilegio favoreció el fraude en el comercio legal. Las cantidades que denunciaron como evadidas los dos oficiales novohispanos pueden ser exageradas, pero la realidad era que la omisión de mercancías o su infravaloración en los registros supuso entre 75 y $80 \%$ de las mercancías negociadas en las flotas (Lorenzo, 1980, p. 378). Formas de eludir el control fiscal era la carga y/o descarga de mercancías fuera de puerto o el cambio entre navíos en alta mar aduciendo que fueron registradas en otros navíos o no pudieron serlo por la premura en la salida de la flota o embarcación.

La existencia de este fraude no se comprendería sin la participación de los mismos oficiales reales e, incluso, de las autoridades, ya que muchos de ellos compraron sus cargos a la corona, sobre todo en el siglo XVII, y necesitaron rentabilizarlos para poder resarcir el desembolso realizado para su consecución.

Para acabar con las evasiones fiscales, la corona elaboró una serie de normas. Los mercaderes o viajeros solían no declarar mercancías que llevaban a América con el fin de sufragar su viaje con su venta u ocultar a la Real Hacienda su existencia y así pagar menos impuesto de almojarifazgo. A partir de este momento, debían declararlas en el correspondiente registro de la embarcación. Así, en 1574 todas las mercancías no declaradas fueron obligadas a pagar en destino el almojarifazgo como si realmente hubiesen sido registradas, incluidas las rescatadas de navíos naufragados (Antúnez, 1797 , p. 216). ${ }^{15}$

14 “...El traer la flota registro es uno de los mayores beneficios que puede tener la Real Hazienda porque con esto se acrezentara el derecho deste puerto mucha suma de ducados pero en dandose el Remedio para la administrazion de la Hazienda buscan los ynteresados modo como çafarse y agora Retienen por haber ganado provission de la audiencia para que los officiales Reales que aqui residimos no podamos abrir fardo para cotexala con la partida de Registro sin que ante todas cossas se de ynformazion de la que en el biene y como este es casso ympusible biene a conseguir lo mismo que tenian quando traian los Registros para cuyo Remedio es necessario mandar V. Mag. que libremente agamos la dicha visita abriendo los fardos y caxas que nos pareciese cotexar los dichos Registros porque de otra manera no se podra conseguir el servicio de V. Mag. y sera principal caussa para que todos registren y paguen el derecho con tanta justificazion deben siendo sin duda esto un genero se trae en cada flota dos millones sin registrar que es en medias y mantas de seda pues por ser tan grandiosa la cantidad que deste genero se gasta en este reino que pasa de $300 \mathrm{U}$ pares de medias de seda y otras tantas mantas no se an nada registrado y otros muchos generos preciossos que vienen metidos en el cuerpo de los fardos dando los cargadores [...] con que pasan en esta aduana por no poder hazer con libertad el examen antes tienen puesto estanco tan digno de recuerdo le hacemos a V. Mag. y para cumplir con las obligaziones de nuestros officios..." Relación que Iñigo Lopez de Salzedo y Domingo de Azpeitia enviaron al rey. 24 de diciembre de 1608. Audiencia de México, leg. 351. AGI.

${ }^{15}$ Cédulas del 21 y 27 de abril de 1574. Recopilación, libro VIII, tít. XV, Leyes VIII y XIX. 
En 1624 el Consulado y la Real Hacienda cambiaron el sistema de cobro del almojarifazgo en un claro intento de evitar el fraude en los registros. A partir de este año, se puso un valor fijo por cada cajón o fardo cargado según peso y mercancías contenidas en ellos. Esta medida contribuyó, aún más, a potenciar el fraude, pues no cargaban los comerciantes las mercancías declaradas, sino otras de valor superior. Además, la necesidad de tener que pesar los fardos antes de ser cargados en los navíos alargó el periodo de carga y, por lo tanto, el de su salida. Este sistema de aforamiento fue sustituido en 1695 por el de palmeo (Antúnez, 1797, pp. 246-247).

La forma de pago del almojarifazgo, en un primer momento, fue en especie, con los mismos productos comerciados, y a partir de 1568 pasó a cobrarse en metálico sin excepciones. En 1620 retornó a la primitiva forma de pago, con lo que hace pensar que ambas formas de cumplir con la Real Hacienda fueron utilizadas paralelamente durante muchos años (Antúnez, 1797, pp. 214-215). ${ }^{16}$

La corona no permitió que el pago de este impuesto fuera aplazado, ${ }^{17}$ aunque la realidad fue otra al permitir a los funcionarios reales el fiado en Sevilla y en América. El pago se realizó con antelación a la venta de las mercancías, reteniéndolas en el caso de no realizarlo. Pero los grandes problemas de liquidez que el sistema comercial establecido originó en los comerciantes hizo que la demora, el fraccionamiento y el crédito en el pago del impuesto funcionaran cotidianamente. Para el caso sevillano hubo que esperar al tornaviaje de la flota para poder pagar el almojarifazgo. En otras ocasiones, los comerciantes adelantaron una parte de la cantidad en que fueron gravadas las mercancías, 5\%, y el resto lo satisfacían con el retorno de la flota o de la embarcación. También se dio el aplazamiento del pago en cuatro años, abonando $70 \%$ del total el primer año y el resto en los tres siguientes.

Estas formas ilegales de pago del impuesto no fueron consentidas por la corona, de ahí que entre 1550 y 1627 se dictaron cinco cédulas reales para combatirlo, ${ }^{18}$ en las que por primera vez sancionaron a aquellos funcionarios que transgredieron las normas con el pago de lo que fiaren, más $4 \%$ en concepto de sanción.

¿Cómo se realizó el cobro del almojarifazgo en Veracruz? Los oficiales de la Caja Real fueron normalmente dos, un tesorero y un contador, y, en muy raras ocasiones, un factor. Su actuación era solidaria y colegiada, como cabe suponerse, ante el Tribunal de Cuentas de México. Una vez que las embarcaciones arribaban al puerto, los maestres de las mismas entregaban

\footnotetext{
${ }^{16}$ Cédulas del 28 de diciembre de 1568 y 9 de marzo de 1620. Recopilación, libro VIII, tít. XV, Ley VI.

${ }^{17}$ Recopilación, libro VIII, tít. XV, Ley V.

${ }^{18}$ Cédulas del 16 de abril y 4 de agosto de 1550, 10 de mayo de 1554, 24 de agosto de 1619 y 23 de enero de 1627. Recopilación, libro VIII, tít. XV, Ley V.
} 
a los oficiales reales los registros. Con los registros en la mano autorizaban la descarga de las mercancías, que quedaban en las bodegas de la Caja Real como garantía del futuro pago del impuesto. Los oficiales, para tener independencia y poder calcular valor e impuesto de las mercancías declaradas, tenían que estar de acuerdo y permanecían solos para evaluarlas. El valor de las mercancías se calculaba, como ya hemos comentado, por el que tuvieren en el puerto a los 30 días de su llegada, teniendo en cuenta el precio medio de su venta al mayoreo (Antúnez, 1797, pp. 235-236; Lorenzo, 1980, p. 380). ${ }^{19}$ Para realizar este cálculo y comprobar o establecer los precios tenían a la mano la normativa del almojarifazgo y estaban acompañados de tres testigos, no mercaderes.

Una vez que el valor de las mercancías había sido establecido, se enviaba a México para que los examinase la Junta de Hacienda, la cual estaba compuesta por el virrey, oidores, fiscal de la Real Audiencia y oficiales de la Caja de México. Se procedía entonces al cálculo de lo que debían pagar los comerciantes por almojarifazgo. Ya calculado el impuesto que debían pagar por la junta, era de nuevo enviado a Veracruz para que los oficiales reales de aquel puerto lo hicieran efectivo. Este sistema fue creado por el virrey Enríquez en 1573 tras consultar con todos los que participaban en el comercio novohispano, incluyendo a los oficiales reales, y fue aceptado por la corona en $1593 .^{20}$

Pero el valor de las mercancías calculadas según los precios existentes en el puerto de Veracruz era ficticio, puesto que muy pocas eran las que se vendían en dicho puerto. Veracruz no fue más que lugar de paso y México fue el encargado de realizar su venta y redistribución al resto del territorio novohispano. Por ello, en 1576 el virrey Enríquez ordenó que fuera calculado el precio de las mercancías según la media del valor más alto, medio y bajo que se hubiere producido en su venta, teniendo en cuenta que esta se producía a crédito (García-Abasolo, 1983, pp. 227-228). A la hora de realizar este cálculo tuvieron en cuenta los gastos de transporte y la degradación de las mercancías por este o por el almacenaje en las bodegas del puerto.

$\mathrm{El}$ hecho de que el verdadero mercado de las mercancías descargadas en Veracruz fuera la capital del virreinato influyó en su recaudación del almojarifazgo. Los comerciantes residían en esta última ciudad, en ella negociaban las mercancías y en ella realizaban el pago de sus impuestos. Los oficiales de la caja veracruzana debían consignar estos pagos como realizados en el mismo puerto, ${ }^{21}$ junto con todos los datos de las embarcaciones. Por cada

${ }^{19}$ Real cédula del 22 de diciembre de 1579 (Antúnez, 1797, pp. 235 y 236).

${ }^{20}$ Para conocer las reformas del Virrey Martín Enríquez véase García-Abasolo (1983, pp. 226227). Para la aceptación de lo estipulado por Enríquez, real cédula del 17 de enero de 1593, diríjase a Antúnez (1797, pp. 239- 240) y Lorenzo (1980, p. 380).

${ }^{21}$ Contaduría, Caja Real de Veracruz, leg. 878. AGI. 
periodo de cuentas de cada oficial real establecían cuatro relaciones, la del almojarifazgo de entrada de embarcaciones procedentes de Sevilla, 10\%; la de entrada de las colonias americanas, $5 \%$; la de salida con destino a la primera, $2.5 \%$, y la de salida con destino a las colonias, $2.5 \%$. Incluían, además del almojarifazgo satisfecho, el tipo y nombre de la embarcación, su maestre, el origen y destino de la misma y la fecha de entrada o salida del puerto. En ocasiones, también consignaban la persona que satisfacía el impuesto en la caja, pero esto se realizó en muy pocas ocasiones.

\section{LA RECAUDACIÓN}

Durante el periodo comprendido entre 1573 y 1650, con lagunas existentes en la documentación, ${ }^{22}$ se recaudaron en la Caja de Veracruz, por concepto de almojarifazgo, un total de 5433564.80 pesos, de los cuales 4957826.40 pesos corresponden a lo cobrado de derechos de importación (91.2\%) y los restantes 475738.40 pesos por la exportación (8.8\%). ${ }^{23}$ A partir de estas dos cantidades y de su evolución hemos calculado el valor total de las mercancías del comercio de Veracruz que ascendió a 72836207 pesos, de los cuales 53798475 pertenecen a las importaciones y 19037732 pesos a las exportaciones. La balanza comercial del puerto, como puede apreciarse, fue negativa con 19037732 pesos. Esta fue compensada con la exportación de numerario, ya estudiada por Hamilton y Lorenzo (véase cuadro 1).

La supremacía de las importaciones sobre las exportaciones fue sustanciosa, sin alcanzar las exportaciones el 10\% de lo comerciado. Eso sí, durante el siglo XVII cambió la tendencia respecto al siglo XVI y las exportaciones tuvieron un porcentaje de participación superior en el comercio veracruzano, $9.1 \%$ contra $7.58 \%$, respectivamente. Las razones de esta diferencia las encontramos en que el comercio importador procedente de Sevilla -las flotas- estaba compuesto fundamentalmente por manufacturas europeas de gran valor y cantidad; mientras que las exportaciones -materias primas en su mayor parte- de menor valor, fueron compensadas por la salida de plata. Como es sabido, el comercio colonial americano se caracterizó por un monopolio de manufacturas europeas y por la falta de una industria local que generase las que importaba.

${ }^{22}$ Desde el 14 de junio hasta el 17 de diciembre de 1594, desde el 6 de mayo hasta el 31 de agosto de 1601, desde el 17 de mayo hasta el 29 de noviembre de 1602, desde junio hasta el 31 de octubre de 1607, desde julio hasta octubre de 1627, desde el 9 de agosto de 1628 hasta el 7 de noviembre de 1630, desde el 4 de noviembre de 1632 hasta el 6 de agosto de 1633 y desde el 5 de septiembre de 1636 hasta el 11 de agosto de 1637.

${ }^{23}$ Contaduría, Caja Real de Veracruz, legs. 878-882, 883, 884 A y B, 885 A y B. AGI. 
CUADRO 1. EXPORTACIONES NOVOHISPANAS DE PLATA DE PARTICULARES, MERCADERES Y BIENES DE DIFUNTOS

\begin{tabular}{lcc}
\hline Año & Hamilton & Lorenzo \\
& & \\
$1571-1575$ & 5250848.60 & 6961106.70 \\
$1576-1580$ & 4452950 & 7071426.70 \\
$1581-1585$ & 7638402.80 & 10010691.00 \\
$1586-1590$ & 6315767.20 & 6003871.10 \\
$1591-1595$ & 9812990.50 & 6174575.60 \\
$1596-1600$ & 7974421.90 & - \\
$1601-1605$ & 5901535.90 & - \\
$1606-1610$ & 7542324.20 & - \\
$1611-1615$ & 6060319.70 & - \\
$1616-1620$ & 8759988.50 & - \\
$1621-1625$ & 8847808.80 & - \\
$1626-1630$ & 4270502.30 & - \\
$1631-1635$ & 2722946.40 & - \\
$1636-1640$ & 4649319.60 & 45453266.70 \\
$1641-1645$ & 2188833.70 & - \\
$1646-1650$ & 2223195.50 & \\
Total & 94612155.60 & \\
\hline
\end{tabular}

Fuentes: Hamilton (1938, pp. 47, 56) y Lorenzo (1980, pp. 252-253).

\section{EVOLUCIÓN Y ETAPAS DE LA RECAUDACIÓN GLOBAL}

A comienzos del reinado de Felipe II, el almojarifazgo recaudado en el puerto de Sevilla supuso entre 54000 y 62000 pesos anuales, para pasar a mediados del siglo XVII los 600000 (Haring, 1979, p. 109). En el caso de Veracruz, entre 1568 y 1571 fueron recaudados 322899 pesos $^{24}$ (Tepaske y Klein, 1988, p. 1); mientras que a mediados del siglo XVII (1646-1650) la cifra alcanzó 291246 pesos $^{25}$ (Tepaske y Klein, 1988, pp. 18-19). El hecho de que estas cantidades fueran tan desiguales entre ambos siglos no significó que existiera una superioridad comercial o recaudatoria entre una y otra época. Las características de la evolución de la cobranza del almojarifazgo en la

${ }^{24}$ Contaduría, Caja Real de Veracruz, leg. 878, ramo 1, desde septiembre de 1568 hasta junio de 1571. AGI

${ }^{25}$ Contaduría, Caja Real de Veracruz, leg. 885B, ramo 7, desde el 5 de octubre de 1646 hasta el 31 de diciembre de 1650. AGI. 
Caja de Veracruz contradicen esta diferencia por la irregularidad del comercio de flotas. Un claro ejemplo, en los primeros quince años del siglo XVII se concentró casi $40 \%$ de lo recaudado, un hecho sintomático de esta irregularidad recaudatoria, la media establecida para el periodo 1601-1615 fue de 152893.24 pesos, comparada con la del total de la recaudación, 69661.1 pesos (véanse gráfica 1 y cuadro 2).

Según los datos de la recaudación anual del almojarifazgo por la Real Caja de Veracruz, hemos establecido cinco diferentes etapas, desarrolladas a continuación.

\section{Primera etapa de auge (1587-1593) ${ }^{26}$}

Tras la epidemia de cocolitze, que asoló Nueva España durante los años 1576 y 1580 y que dejó sin mano de obra indígena y sin consumo a la economía del virreinato (García-Abasolo, 1983, pp. 67-86), y de la crisis y bancarrota de la monarquía de 1576 a 1577 (Carlos, 2013, pp. 59-128; Yun y Comín, 2011, pp. 5-11), comenzó a partir de 1588 una etapa de auge en la recaudación del almojarifazgo y, por lo tanto, del comercio del puerto de Veracruz.

En estos ocho años el importe ingresado por este derecho ascendió a 642638.9 pesos, $11.83 \%$ del total recaudado. A pesar de que el tráfico de flotas no fue constante, no las hubo de llegada en 1587, 1589 y 1592, ni de salida en 1587, 1588, 1589 y 1593 . Se recaudaron por concepto de importación 581949.1 pesos (90.56\%); mientras que el comercio de exportación, al margen de flotas, tan sólo supuso 60689.8 pesos, $9.44 \%$ (véase gráfica 2).

La economía novohispana sufría, por aquel entonces, una serie de carencias de manufacturas que, como hemos explicado anteriormente, fueron suplidas desde Sevilla; tal era el caso del vino y del aceite andaluz. Estas importaciones estaban destinadas en su mayor parte para la población de origen europeo. La evolución de este tráfico condicionaba el desarrollo del tráfico intercolonial, puesto que Veracruz hacía de reexportador de los sobrantes de las flotas hacia el área de influencia de su comercio, el Caribe.

\footnotetext{
${ }^{26}$ Contaduría, Caja Real de Veracruz, leg. 878, ramo 3, desde el 11 de agosto de 1572 hasta el 30 de junio de 1573; 879, ramos 1 y 2, desde junio de 1587 hasta el 13 de junio de 1591 , y 880, ramos 1-4, desde el 30 de junio de 1590 hasta el 14 de junio de 1594 . AGI.
} 


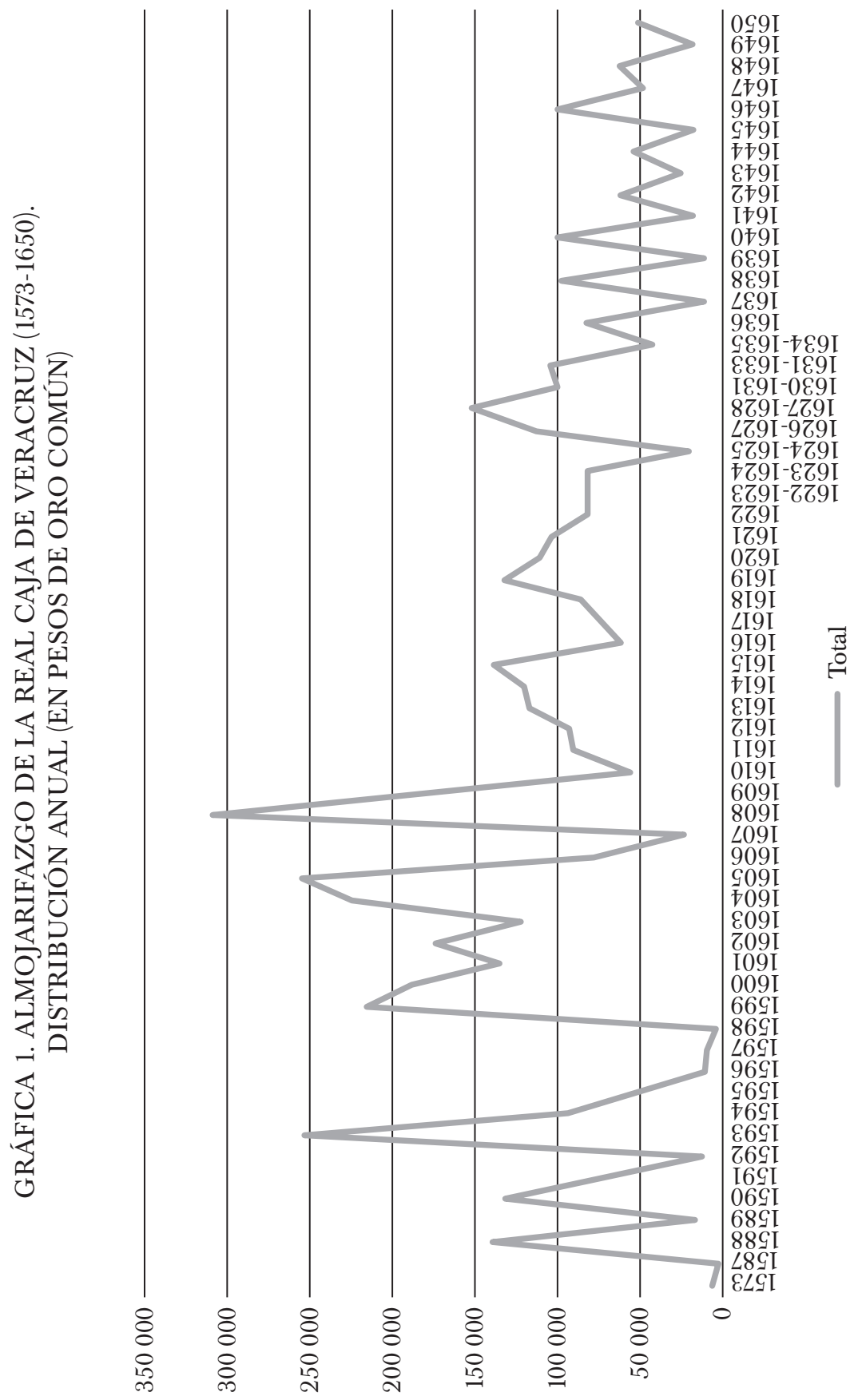

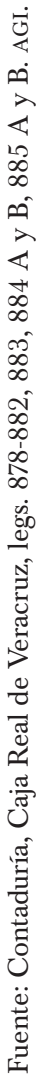




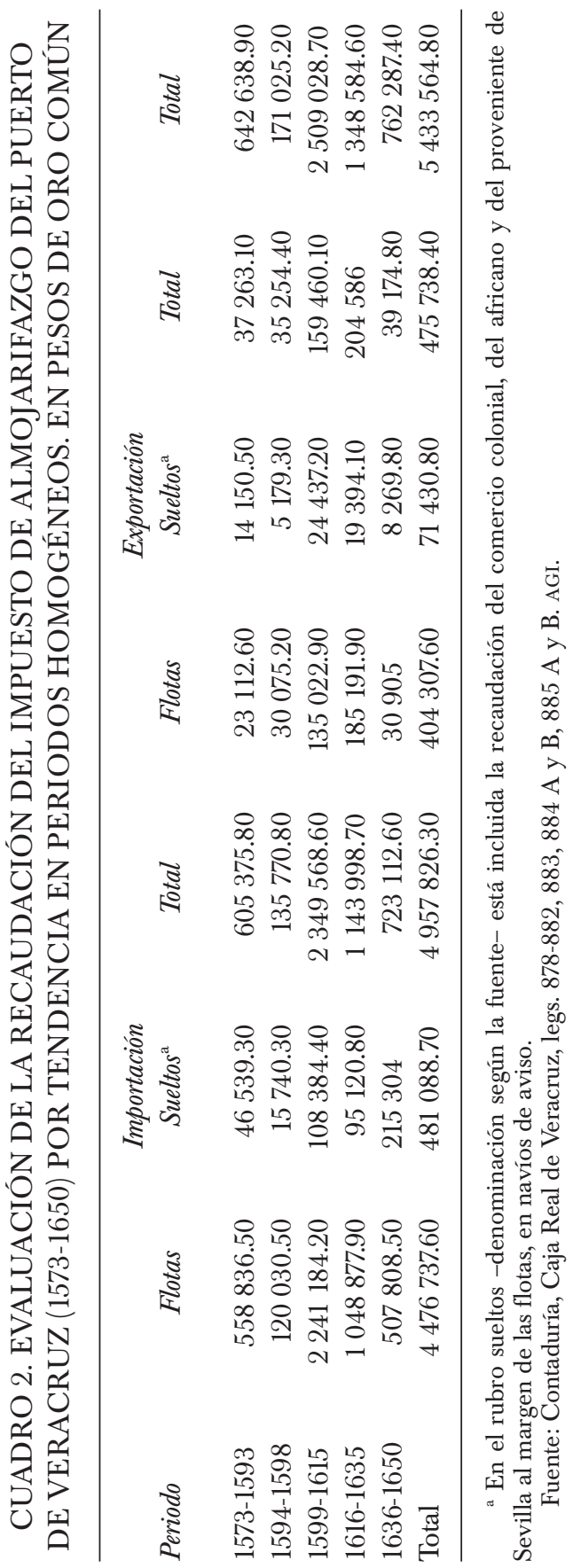




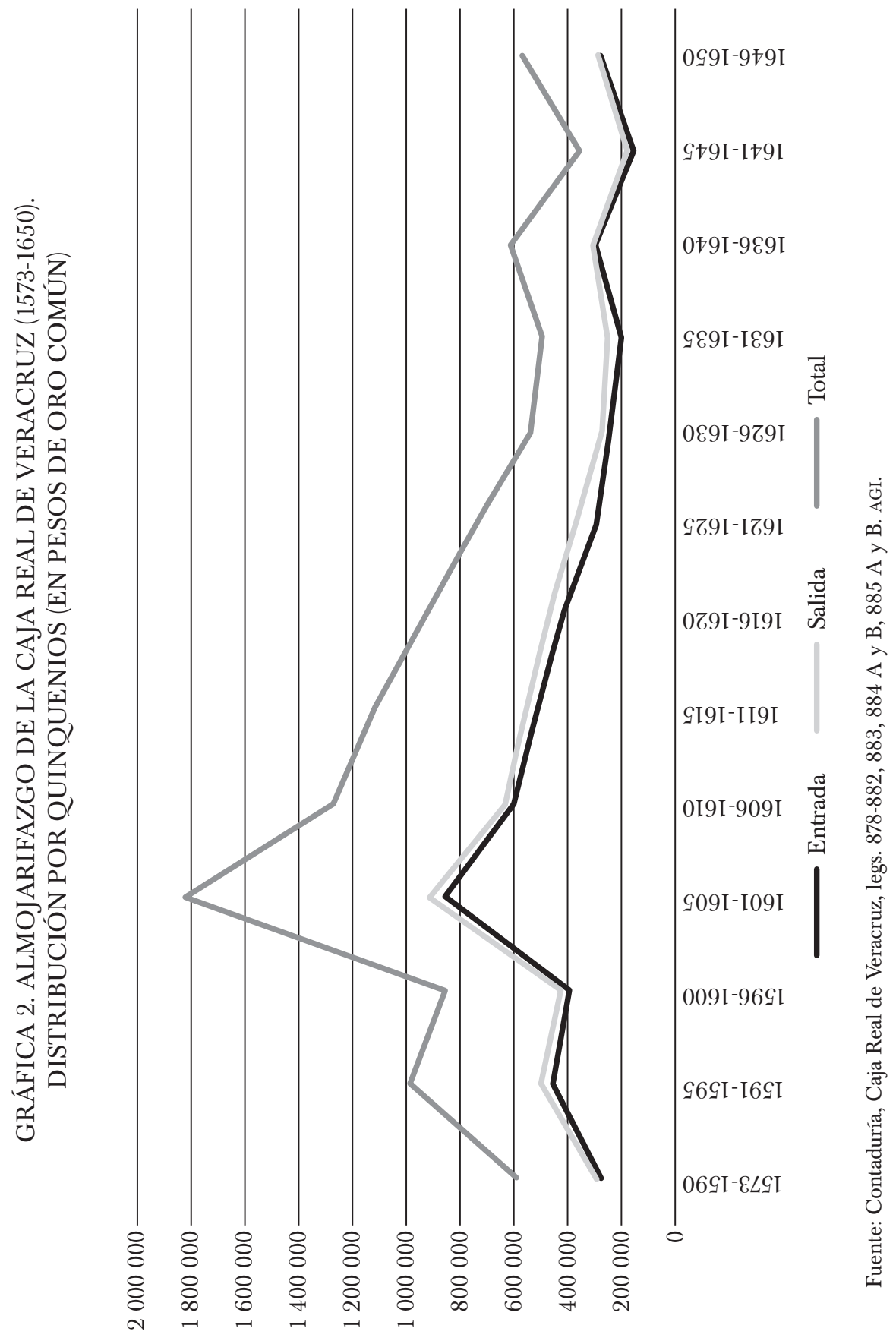




\section{Primera etapa de crisis (1594-1598) ${ }^{27}$}

La política europea de la corona castellana condicionó la evolución del tráfico mercantil entre los dos continentes y entre las mismas colonias. Así las guerras de fines del siglo XVI con Holanda y Francia, aliadas de Inglaterra, influyeron en el tráfico y en la recaudación del almojarifazgo. Se produjo un hostigamiento a las flotas por parte de estos países y por piratas, incluidos ingleses. Durante este periodo vemos cómo se redujo el volumen y el valor de lo negociado entre Sevilla y México, originando una corta etapa de crisis. Tras la firma del Tratado de Vervins (1598), esta tendencia cambió. También influyeron las crisis y bancarrotas de la monarquía de 1596 y 1598; esta última afectó financieramente tan sólo a las instituciones comerciales sevillanas en 1600 y 1601 (Carlos, 2013, pp. 59-128; Yun y Comín, 2011, pp. 5-11).

En esta etapa la recaudación se redujo a 171025.2 pesos, 3.15\% de lo ingresado en la caja para todo el periodo, una cuarta parte de la cantidad recaudada en la etapa anterior. De esta cifra, 150105.8 pesos procedían de las mercancías del comercio intercontinental (87.77\%), 120030.5 pesos de importación y 30075.3 de exportación. La tendencia del comercio intercolonial en la recaudación de estos años fue ligeramente superior a los anteriores, pasando de 9.44 a 12.23\% (20 919.4 pesos), un tercio por debajo de aquella.

Si bien el cobro del impuesto procedente de las flotas de entrada y al comercio intercolonial se redujo, en las exportaciones de las primeras se produjo un incremento de $30.13 \%$ respecto a la etapa anterior, lo que constituyó el comienzo de una etapa de expansión de las exportaciones veracruzanas con destino a la metrópoli en las flotas que perduró hasta 1616.

\section{Segunda etapa de auge (1599-1615) ${ }^{28}$}

Desaparecidos los problemas políticos que interferían en el desarrollo normal del comercio intercontinental, a partir de 1599 la recaudación del almojarifazgo recaudado por la Caja de Veracruz muestra una tendencia alcista. La afluencia de flotas a Nueva España fue constante, salvo en 1607 que no la hubo por la presencia de una flota holandesa en las costas de la península

${ }^{27}$ Contaduría, Caja Real de Veracruz, leg. 880, ramo 4, desde el 20 de octubre de 1592 hasta el 14 de junio de 1594 , y 881, ramos 1 a 5 , desde el 19 de octubre de 1594 hasta el 1 de enero de 1600. AGI.

${ }^{28}$ Contaduría, Caja Real de Veracruz, leg. 881, ramo 4, desde el 26 de mayo de 1598 hasta el 1 de enero de $1600 ; 882$, ramos 1-11, desde el 7 de mayo de 1600 hasta el 14 de octubre de 1609 , y 883 , ramos 1-7, desde el 14 de octubre de 1609 hasta el 12 de junio de 1616. AGI. 
ibérica, ${ }^{29}$ y en su lugar fue enviada una armadilla con los azogues necesarios para las minas novohispanas y algunas mercancías. En 1607 hubo una bancarrota de la monarquía que no afectó al comercio y a la recaudación del impuesto del almojarifazgo (Carlos, 2013, pp. 59-128; Yun y Comín, 2011, pp. 5-11).

La realidad pudo ser otra, la saturación de los mercados. Ya en 1606 se produjo una importante reducción en la recaudación procedente de las flotas respecto al año anterior, de los 240837.9 pesos de 1605 se pasa a 69643.5 pesos de 1606 y a 2962.3 pesos de 1607. El Consulado de México alegó como causa de esta disminución la peligrosidad en la navegación.

En estos 17 años se ingresaron en la caja un total de 2509028.7 pesos, $46.18 \%$ del total. De esta cantidad, 2376207.1 pesos (94.7\%), correspondieron al comercio intercontinental de flotas, mientras que el 5.3\% restante fue recaudado del comercio intercolonial.

Si bien el margen de participación del comercio intercolonial en los ingresos fue menor que en la etapa anterior, 5.3\% frente a 12.23\%, el valor medio anual de los mismos fue superior, incluso lo duplica, 7813 pesos contra 3 486.6. El comercio de flotas eclipsó en estos años al realizado marginalmente fuera de ellas, aunque fuese próspero.

\section{Segunda etapa de crisis (1616-1635)}

La saturación de los mercados coloniales propició una reducción de las importaciones procedentes de la metrópoli. Este hecho originó que los comerciantes sevillanos optaran por el desabastecimiento de los mercados coloniales con el fin de poder colocar sus productos. Este desabastecimiento favoreció formas alternativas de paliar la escasez de manufacturas, como el contrabando, el surgimiento de una industria autóctona capaz de sustituir los productos importados en las flotas o su abastecimiento a través del galeón de Manila. La bancarrota de 1627 afectó a los mercados financieros europeos y, por ende, al comercio global en general y con América en particular. (Carlos, 2013, pp. 59-128; Yun y Comín, 2011, pp. 5-11).

Así quedó reflejado en la recaudación del almojarifazgo en Veracruz, que en esta etapa quedó reducida a 53.75\% respecto a la anterior, 1348584.6 pesos, 24.82\% del total recaudado, de los cuales 1234069.8

${ }^{29}$ Consulado, libro I, fs. 162-165. AGI.

${ }^{30}$ Contaduría, Caja Real de Veracruz, leg. 883, ramos 7-14, desde el 11 de junio de 1615 hasta el 14 de octubre de $1622 ; 884 \mathrm{~B}$, ramos $1-9$, desde el 5 de septiembre de 1622 hasta el 14 del mismo mes de 1627, y 884A, ramos 1-10, desde el 14 de septiembre de 1627 hasta el 4 del mismo mes de 1636. AGI. 
pesos correspondieron al comercio intercontinental o de flotas $(91.51 \%), y$ 114514.9 pesos al intercolonial.

Este descenso en los ingresos fiscales fue más notorio en las importaciones, que se redujeron a 1048877.9 pesos; mientras que, por otro lado, las exportaciones se incrementaron 37.15\%. Este incremento corroboraría la buena salud de la economía novohispana.

\section{Crisis (1636-1650) $)^{31}$}

La depresión producida en la etapa anterior se incrementó al cambiar la periodicidad de las flotas, pasó a ser cada dos años. No hubo flotas de entrada en el puerto de Veracruz en los años 1637, 1639, 1641, 1643, 1645 y 1649 , como tampoco las hubo de salida entre 1634 y 1638 y en 1640,1642 , 1644 y 1646. Estas ausencias quebrantarán notablemente los ingresos de la caja del puerto, que en estos quince años se contabilizaron en ella tan sólo 762287.4 pesos, que representaron $14.03 \%$ del total y una reducción de $43.47 \%$ menos. La bancarrota de 1627 se prolongó en el tiempo y en 1647 se reprodujo, creando una atmósfera de descrédito de la corona y sus instituciones, y que afectó al comercio con América en cuanto a la falta de liquidez (Carlos, 2013, pp. 59-128; Yun y Comín, 2011, pp. 5-11).

Las consecuencias de este descenso en la actividad mercantil intercontinental afectó el intercambio intercolonial del puerto novohispano en sus exportaciones, que quedaron reducidas a la mitad. Por el contrario, las importaciones procedentes de los mercados coloniales incrementaron en $126.35 \%$ por la irrupción del cacao venezolano en Nueva España y por la prohibición del comercio con Perú (Arcila, 1993, pp. 251-252; Borja y Szászdi, 1964, p. 5; Calderón, 1988, p. 586), que eleva este comercio $29.33 \%$, frente a $8.49 \%$ de la etapa anterior (véase cuadro 3 ).

\section{CONCLusiones}

El comercio colonial estuvo gravado por varios impuestos que recaudaba la Real Hacienda, tales eran la avería, el derecho de toneladas, el almirantazgo, la lonja, el consulado o el almojarifazgo, entre los más importantes. Hubo exenciones en el cobro del almojarifazgo, bien por causas políticas o económicas, y casos de fraude y de contrabando por el elevado porcen-

\footnotetext{
${ }^{31}$ Contaduría, Caja Real de Veracruz, leg. 884A, ramo 10, desde el 19 de noviembre de 1634 hasta el 4 de septiembre de 1636; 885A, ramos 1-6, desde el 12 de agosto de 1637 hasta el 4 de octubre de 1646, y 885B, ramo 7, desde el 5 de octubre de 1646 hasta el 15 de diciembre de 1650 . AGI.
} 


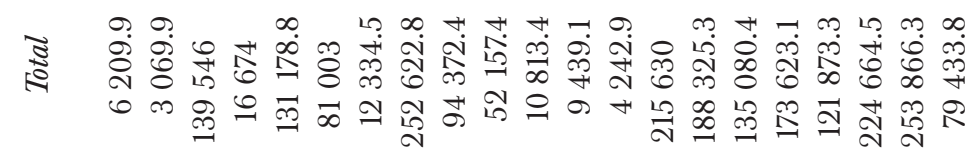

过台

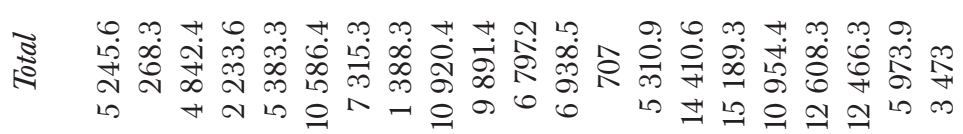

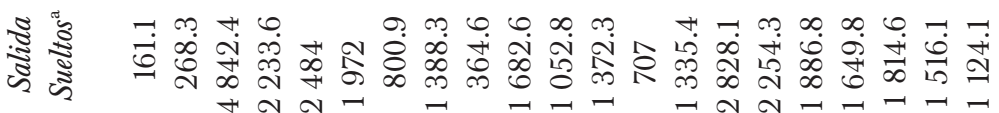

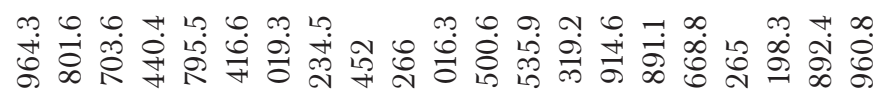

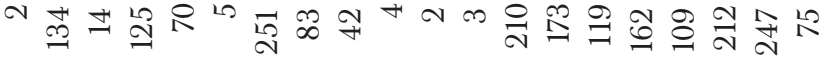

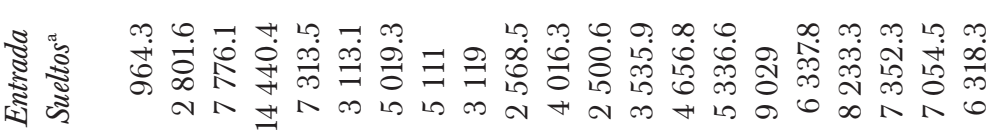




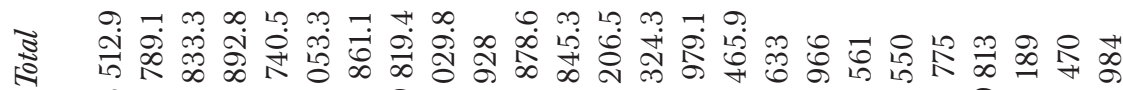

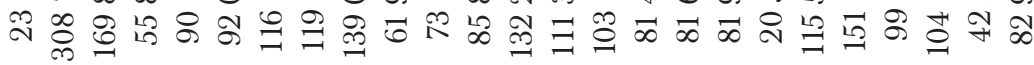

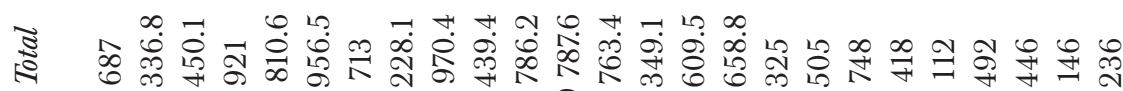

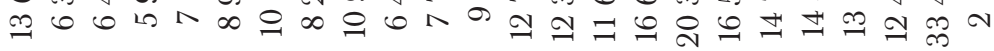

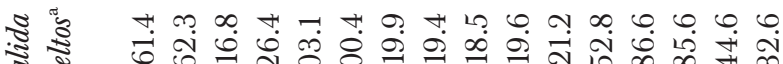

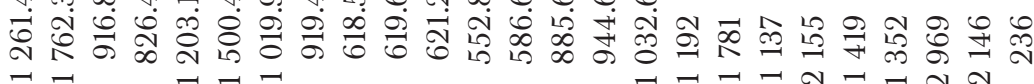

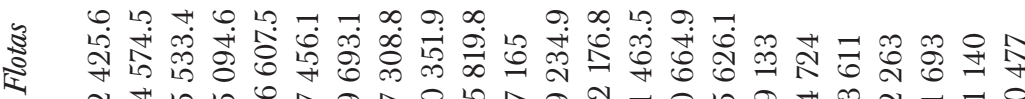

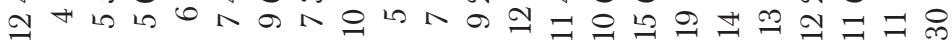

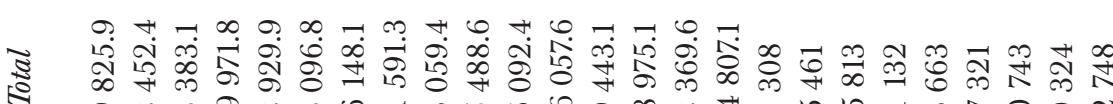

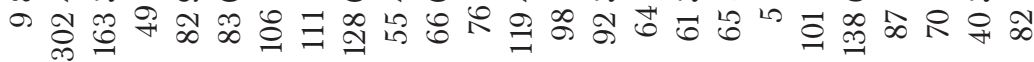

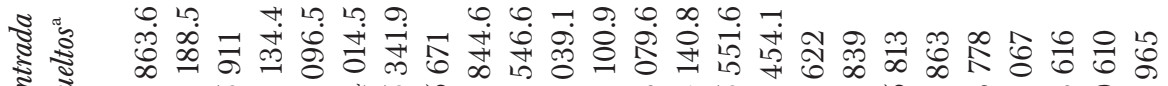

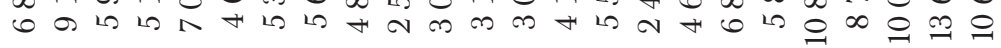

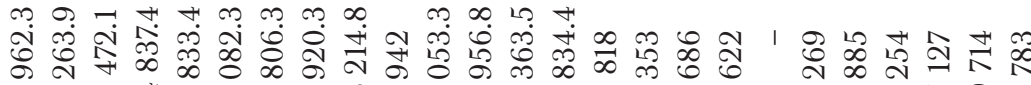

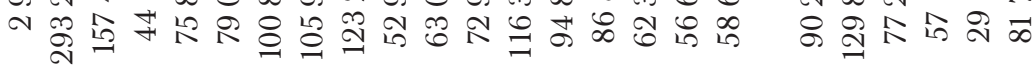

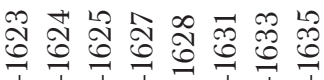

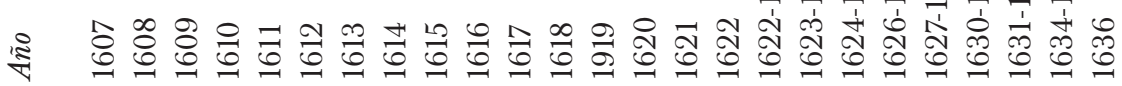




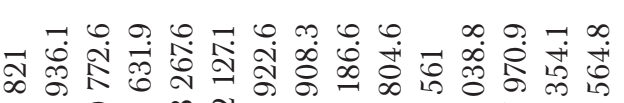

$=\mathscr{0} \bigcirc \Omega \infty$ ำ

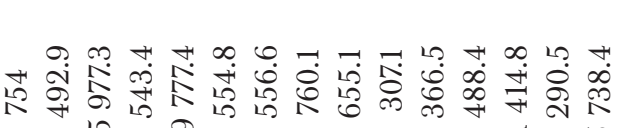
0 m-・ー年

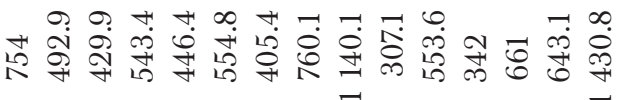

$$
\text { ト }
$$

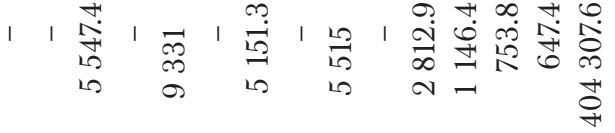

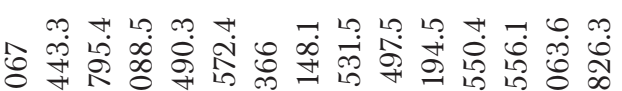

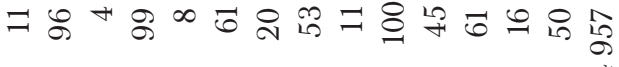

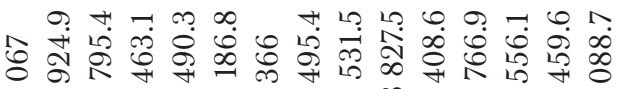
$\exists$ 늑 $+0 \infty$ 의 워

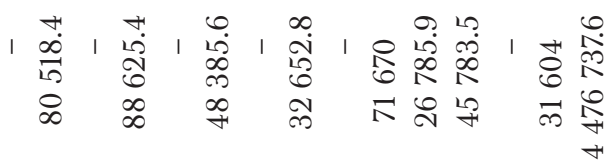

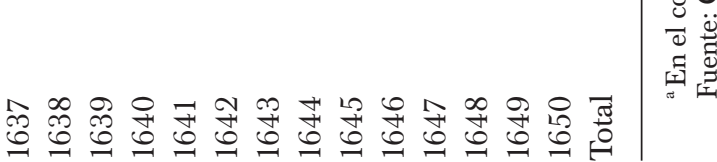


taje estipulado de almojarifazgo que los incentivó, que no desmerecen los datos aportados.

El almojarifazgo recaudado en la Real Caja de Veracruz durante el periodo de 1587 a 1650 fue de 5433564.8 pesos. Hemos calculado que de esta cantidad, 4957826.3 pesos (91.2\%), procedió del comercio de importación y 475738.4 pesos, el 21.8\% restante del de exportación. Esto supuso, según nuestros cálculos, un valor de mercancías intercambiadas en el puerto de 72836207 pesos para este periodo.

La periodificación de la recaudación que hemos establecido nos deja dos etapas de auge y tres de crisis. A pesar de que comienza el estudio con malos augurios por el desarrollo de la epidemia de Cocolitzi (1576-1577) y por las bancarrotas de la monarquía (1557 y 1576-1577), la recaudación del impuesto va a ir creciendo paulatinamente con los altibajos de crisis y auges estableciéndose una media anual de 69661.1 pesos. Por regla general, en todas las etapas se suceden las bancarrotas y crisis fiscales de la monarquía hispánica, la cancelación de flotas entre Europa y América y las políticas belicistas.

En la primera etapa de auge (1587-1593), a pesar de la ausencia de flotas de entrada en 1587, 1589 y 1592, y de salida en 1587, 1588, 1589 y 1593, la recaudación del almojarifazgo supuso $11.83 \%$ del total. Esta etapa está caracterizada por un incremento de las necesidades de consumo de manufacturas europeas por parte de los colonizadores españoles.

A continuación, se desarrolló una disminución en la recaudación, que he denominado como primera etapa de crisis, entre 1594 y 1598 , en la que las guerras europeas, la piratería y las bancarrotas de 1596 y 1598 influyeron en el normal desarrollo del comercio y, por ende, en la recaudación del almojarifazgo. La recaudación supuso 3.15\% del total. A pesar de esta reducción, hubo un leve ascenso de lo cobrado en al comercio intercolonial de Veracruz y de las exportaciones a Europa, 30.13\%, que va a perdurar hasta 1616 .

Tras la firma del tratado de Vervins (1598) llegó un periodo de tranquilidad bélica que va a perdurar hasta 1615 y que va a influir en la recaudación del puerto de Veracruz. A pesar de la bancarrota de 1607, se caracterizó esta etapa (1599-1615) por una constancia en la arribada de flotas. Aunque ya comenzó a percibirse una saturación de los mercados (1605-1607), el porcentaje de lo recaudado supuso 46.18\% del total. Debemos destacar un protagonista, el comercio intercolonial, cuyo dinamismo llegó a duplicar la recaudación del almojarifazgo por este concepto.

A partir de 1616 el comercio y la recaudación del impuesto entró en una crisis de la que ya no salió. En dos periodos diferentes, la evolución del mismo fue de mal en peor. Las bancarrotas de 1627 y 1647, que afectaron al sistema financiero europeo, así como la saturación del mercado no- 
vohispano y la política de los comerciantes de desabastecer los mercados con el fin de aumentar la demanda, redujeron la recaudación entre 1616 y 1635 a $24.82 \%$ del total, es decir, a la mitad de la que hubo en el periodo anterior. Supuso también la irrupción del contrabando, de la sustitución de las importaciones por la producción interior y del desarrollo del galeón de Manila. Puede verse este fenómeno por un incremento de las exportaciones en 37.15 por ciento.

Como prolongación de estos años, en 1636, y hasta el final del periodo estudiado, se produjo una importante reducción en la recaudación del almojarifazgo. Entre 1636 y 1650 se recaudó tan sólo $14.03 \%$ del total, $43.47 \%$ menos que en el periodo inmediato anterior. Causas hubo muchas, destacamos la reducción en la periodificación de las flotas en ambos sentidos. La recaudación procedente de las exportaciones a los mercados coloniales del área de influencia del puerto de Veracruz se vio reducida a la mitad; por el contrario, la de las importaciones coloniales se incrementaron $126.35 \%$ debido a la irrupción del cacao venezolano y a la prohibición del comercio con Perú.

En definitiva, la evolución de la recaudación global del almojarifazgo en el puerto de Veracruz entre 1573 y 1650 demuestra una tendencia hacia la crisis originada por una mala política económica, fiscal y de relaciones internacionales, enmarcada dentro de la que se va a desarrollar en Europa en el siglo XVII. Por el contrario, si discriminamos entre recaudación procedente del comercio intercontinental e intercolonial, se demuestra que, mientras el primero entró en una crisis aguda, el segundo fue en constante auge.

\section{LISTA DE REFERENCIAS}

AnTúnEz, R. (1797). Memorias históricas sobre la legislación y gobierno del comercio de los españoles con sus colonias en las Indias Occidentales. Madrid: Imprenta de Sancha.

ARCILA, E. (1993). Hacienda y comercio de Venezuela en el siglo XVI. Caracas: Banco Central de Venezuela.

Ayala, M. (1988). Diccionario de gobierno y legislación de Indias. Madrid: Ediciones Cultura Hispánica.

Borah, W. (1975). Comercio y navegación entre México y Perú en el siglo XVI. México: Instituto Mexicano de Comercio Exterior.

BorJa, D. y SzÁszDI, A. (1964). El comercio del cacao de Guayaquil. Revista de Historia de América, 57-58, 1-50. Recuperado de http://www.jstor.org/stable/20138626

Borrego, M. (1983). Cartagena de Indias en el siglo XVI: contribución a la conmemoración del $V$ Centenario del Descubrimiento. Sevilla: Escuela de Estudios Hispano-Americanos. 
Calderón, F. (1988). Historia económica de la Nueva España en tiempos de los Austrias. México: Fondo de Cultura Económica.

Carlos, C. J. (2013). Endeudamiento dinástico y crisis financieras en tiempos de los Austrias: las suspensiones de pagos de 1557-1627. Libros de la Corte, 7(5), 59-128.

Celaya, Y. (2010). La cesión de un derecho de la Real Hacienda: la administración del impuesto de la alcabala novohispana en el siglo XVII. Tres estudios de caso. América Latina en la Historia Económica, 17(1), 91-125. DOI: 10.18232/alhe.v17i1.430

CÉspedes, G. (1945). La avería en el comercio de Indias. Sevilla: Escuela de Estudios Hispano-Americanos.

Chaunu, P. (1960). Veracruz en la segunda mitad del siglo XVI y primera del XVII. Historia Mexicana, 9, 521-557.

Fuentes, A. (1991). Los ingenios de azúcar en La Habana del siglo XVII (1640-1700): estructura y mano de obra. Revista de Historia Económica/Journal of Iberian and Latin American, 9(1), 35-67. DOI: 10.1017/S0212610900002615

García, A. (2014). Tierra adentro, mar en fuera. El puerto de Veracruz y su litoral a Sotavento, 1519-1821. México: Fondo de Cultura Económica/Universidad Veracruzana.

García-Abasolo, A. (1983). Martín Enríquez y la reforma de 1568 en Nueva España. Sevi1la: Diputación Provincial.

GiL, E. (1986). El almojarifazgo como índice de interpretación del comercio del puerto de Veracruz, 1600-1622. Estudios de Historia Social y Económica de América, 2, 89-119. Recuperado de http://hdl.handle.net/10017/13601

GiL, E. (1990). El tráfico del puerto de Veracruz en 1572. Estudios de Historia Social y Económica de América, 7, 19-26. Recuperado de http://hdl.handle.net/10017/5759

GiL, E. (1993). Auge y crisis del tráfico comercial veracruzano visto a través de la cuenta de almojarifazgo, 1573-1650 (Tesis doctoral). Universidad de Alcalá, España.

GiL, E. (1997). Interpretación del comercio de un puerto colonial novohispano durante un periodo de crisis, Veracruz (1587-1650). Estudios de Historia Social y Económica de América, 14, 75-123. Recuperado de http://hdl.handle.net/10017/5977

Hamilton, E. J. (1938). Revisions in economic history VIII. The Decline of Spain. The Economic History Review, 8(2), 168-179. DOI: 10.1111/j.1468-0289.1938.tb00930.x

HaRing, C. H. (1979). Comercio y navegación entre España y las Indias en la época de los Habsburgo. México: Fondo de Cultura Económica.

Jumar, F. A. (2004). El comercio atlántico de Río de La Plata, 1680-1778. El circuito legal español. Las fuentes utilizadas y su tratamiento. América Latina en la Historia Económica, 11(1), 11-36. DOI: 10.18232/alhe.v11i1.332

Lorenzo, E. (1980). Comercio de España con América en la época de Felipe II (t. II). Valladolid: Institución Cultural Simancas.

Miranda, J. (1962). España y Nueva España en la época de Felipe II. México: Universidad Nacional Autónoma de México.

Moreyra, M. (1944). Estudios sobre el tráfico marítimo en la época colonial. Lima: Librería e Imprenta Gil. 
Recopilación de leyes de los reynos de Las Indias (1681) (t. VIII, tít. XV. De los almojarifazgos y derechos reales). Madrid: Julián de Paredes. Recuperado de http://fondosdigitales.us.es/fondos/libros/752/14/recopilacion-de-leyes-de-los-reynos-de-las-indias/

SALAS, L. (2007). Nobleza y fiscalidad en la Ruta de las Indias: el emporio señorial de Sanlúcar de Barrameda (1576-1641). Anuario de Estudios Americanos, 64(2), 13-60. DOI: 10.3989/aeamer.2007.v64.i2.80.

SALAS, L. (2012). Los antepuertos de Sevilla: señorío, comercio y fiscalidad en la Carrera de Indias (s. XVI). En E. VIla y J. Lacueva (coords.), Mirando las dos orillas: intercambios mercantiles, sociales y culturales entre Andalucía y América (pp. 105-127). Sevilla: Fundación Buenas Letras.

Tepaske, J. J. y Klein, H. S. (1988). Ingresos y egresos de la Real Hacienda de Nueva España. México: Instituto Nacional de Antropología e Historia.

VAlle, G. (2003). Gestión del derecho de alcabalas y conflictos por la representación corporativa: la transformación de la normatividad electoral del Consulado de México en el siglo Xvir”. En B. Hausberger y A. Ibarra (eds.), Comercio y poder en América colonial: los consulados de comerciantes, siglos XVII-XIX (pp. 41-72). MadridFrankfurt del Main-México: Iberoamericana/Vervuert/Instituto Mora.

VILA, E. (1974). Historia de Puerto Rico: 1600-1650. Sevilla: Escuela de Estudios Hispano-Americanos-Consejo Superior de Investigaciones Científicas.

Yun, B. y Comín, F. (2011). La crisis de la deuda pública en España (siglos XVI-XIX). $X$ Congreso Internacional de la Asociación Española de Historia Económica. Carmona: Universidad Pablo Olavide.

\section{Archivos}

AGI Archivo General de Indias, Sevilla, España. 